\title{
Sexual size dimorphism variation in altitude gradients in ground beetles (Coleoptera, Carabidae)
}

\author{
Tatiana Ananina ${ }^{1,2, *}$, Raisa Sukhodolskaya $^{3}$, Anatoliy Saveliev $^{4}$, and Tamara Avtaeva ${ }^{5}$ \\ ${ }^{1}$ United Administration of Barguzinsky State Natural Biosphere Reserve and Zabaikalsky National Park» (FSE \\ "ZapovednoePodlemorye"), Ulan-Ude 670045 Russian Federation \\ ${ }^{2}$ Institute of General and Experimental Biology Siberian Branch of the Russian Academy of Sciences; Ulan-Ude, 670047 Russian \\ Federation \\ ${ }^{3}$ Laboratory of Biomonitoring Institute of Problems in Ecology and Mineral Wealth Academy of Sciences of Tatarstan Republic, \\ Kazan, 420087 Russian Federation \\ ${ }^{4}$ Department of Ecosystem Modeling, Kazan (Volga Region) Federal University, Kazan, 420000 Russian Federation \\ ${ }^{5}$ Chechen State Pedagogical University, Grozniy, 364050 Russian Federation
}

\begin{abstract}
In this study, we verified the theory about the greatest steepness in body size variation in insects males compared with females in altitude gradients. As the model, ground beetles took as the appreciated bioindicators. We sampled three species of carabids at two regions: Carabus odoratus and Pterostihusmontanus were sampled at four elevations at Barguzin Ridge (N 54 20'; E 109 30', Russia) and Carabus exaratus - at three elevations in mountainous terrain in Chechnya Republic (42088' N 46044'E Russia). We measured more than 1000 individuals by six linear traits and construct regression models of females' and males' size variation along elevation gradients. The regression slopes in the majority of the overwhelming case (14 models out of 18 ) were sex-biased. In P. montanus elytra length variation and $C$. exaratus traits width variation, the slopes differed in males and females only: In the first case, trait value in females significantly increased and in the second traits values varied in opposite directions. Therefore, we did not find evidence of greater steepness in male traits variation in ground beetles.
\end{abstract}

\section{Introduction}

Sexual size dimorphism (SSD) is the most obvious difference between both sexes in the majority of animals. In endotherms (mammals and birds), males are frequently larger than females, whereas, in ectotherms, females tend to be larger. Nevertheless, in insects, a variety of situations occurs even within families or subfamilies. The subject of our investigations is ground beetles. As the rule, SSD in them is female-biased [1]. Carabids are widely distributed, allowing to examination of large data arrays. For example, vast investigations carried out in Russia and adjacent countries. Bergmann, converse Bergmann and saw-tooth patterns in body size variation in several species of carabids were shown [2, 3]. Additionally, linear modeling detected environmental factors affecting morphometric structure in carabid assemblages [4-7]. No less attention was paid to sexual size dimorphism and its variation in species studied $[8,9]$. In this paper, we continue the theme of body size and sexual size dimorphism variation in altitude gradient. Long-termed investigations in three carabid species showed that body size variation in altitude gradient is usually similar in the direction in both sexes. However, sometimes this phenomenon took on different meanings. Those processes certainly affected SSD value at different elevations. Thus, in Pterostichus montanus the highest values of SSD in all traits were registered at low mountains populations (compared with the coast, middle- and high mountains) [10]. In Carabus odoratus traits size values monotonically decreased in altitude gradient, but SSD values were the highest at the coastal and high mountains populations [11]. Preliminary unpublished results for a third species, Carabus exaratus, indicate that the parameters of the elytra and pronotum decreased from plain to mountain populations. However, the trend reversed in head variation. The morphometric characters of the lowland, foothill, and mountain populations differed significantly [12]. In this study, we continue to explore the features of SSD variation. That variation in body size in geographic gradients differs between sexes: the steepness of shifts is more in males than in females [13]. One of the papers tried to argue: modeling size shifts in males and females in latitude gradient did not prove that thesis for ground beetle Pterostichus oblongopunctatus [14]. The aim of this paper is the estimation of differences in steepness of body size

\footnotetext{
*Corresponding author: t.l.ananina@mail.ru
} 
variation in males and females in altitude gradients. We could not hypothesize anything before the work would be finished, because we could not find any publication on that theme.

\section{Materials and methods}

\subsection{Research objects}

Pterostichus (Petrophilus) montanus Motschulsky, 1844 is a boreal Eastern Palaearctic species; it distributed from the Ural to the Far East and northern Mongolia [15]. It is a mountain - forest; one of the dominant species of the Barguzin Ridge, a one-year life cycle, the sex ratio in all divisions, with the exception of the lowest one, the blueberry larch, shifted in favor of males [16].

Carabus odoratus Motchulsky, 1844 distributed from the Yamal Peninsula and all around Siberia to the Magadan area and the Kamchatka Peninsula, in southern Siberia from Altai up to the Khabarovsk territories. Many unequally differing populations inhabit this area. A considerable number of forms of $C$. odoratus described at present. The majority of intraspecific names treated as synonyms. The species has a large number of subspecies and local forms. In the Siberia and north of the Russian Far East, the species represented by 20 subspecies. The species occurs in the forest and mountain tundra at altitudes from 1500 to $2600 \mathrm{~m}$ above sea level [17]. In our study, we used Carabus odoratus barguzinicus Shil. 1996. It is the Baikal subspecies of Siberian species, endemic, and generalist in Barguzin Ridge [18].

C. exaratus Quencel, 1805 is an endemic of the Caucasus, a eurytopic species with forest and forestmeadow features, has a spring-summer type of reproduction, an autumn recycling [19]. This species has spread from the foothill steppes to the subnival zone, dominates in mountain slopes and floodplain forests. C. exartus inhabits the floodplain forests of the Tersko-Kuma lowland and high-mountainous steppe areas, hornbeam and beech forests of the high belt of the Black Mountains, and also in the plains of the Ciscaucasia [20].

\subsection{Study area and collection of material}

The key site of entomological research is located at Barguzin State Natural Biosphere Reserve (N 54 20'; E $109^{\circ} 30^{\prime}$, Russia). It is on the northeastern coast of Lake Baikal. The climate is sharply continental, with marine features. The area is by frosty long winters and cool short summers. The continentality of the climate somewhat decreases during the transitional seasons of the year: in spring, Baikal cools the air, and in autumn, it gives off heat. On the western macroslope of the Barguzinsky Ridge, the development of a special wet Baikal type of zonation associated with the inversion phenomenon is noted. Thus, on the shores of Lake Baikal, a pseudo subalpine belt formed (larch forests and clumps of dwarf cedar), which do not rise above $100 \mathrm{~m}$ above the lake level. Analogs located on the coast of the Sea of Okhotsk only [21]. The study area is characterized by a relatively gentle uplift from the shore of Lake Baikal (454-460 m above sea level) to the low-mountain part of the ridge (at elevations of $535-721 \mathrm{~m}$ ), steeper to the upper border of the forest $(1407 \mathrm{~m})$, and a sharp rise to the highest point of the watershed ridge $(1667 \mathrm{~m})$. Entomological sites were located in nine characteristic biotopes in a $30-\mathrm{km}$ highaltitude transect in the Davsha river valley, from the shore of the Lake Baikal to the subalpine belt. Following the landscape features of the study area, high-altitude sections we designated: coast, $458-500 \mathrm{~m}$ above sea level; low mountains (the lower part of the mountain forest belt, 501-720 m); middle mountains (the upper part of the mountain - forest belt, 721-1004 $\mathrm{m}$ ), and high mountains (subalpine vegetation belt, $1005-1667 \mathrm{~m})$. In the coastal transect part, the following biotopes investigated: blueberry cedar and herbaceous birch forest; in the low-mountainous, blueberry larch and bergenia cedar; in the middlemountainous area, bergenia aspen and blueberry fir; and, in the high mountainous, park birch, blueberry tundra, and lichen tundra. For morphometric measurements, we used collection samples of ground beetles from standard soil traps on constant entomological sites. Sexually mature intact specimens we selected for analysis, taking into account the habitat, but without fixing the sampling time (year, month, and decade). In total, 968 specimens we measured from Barguzin Ridge.

Specimen of $C$. exaratus we sampled in Chechen Republic $\left(42^{\circ} 88^{\prime} \mathrm{N} 46^{\circ} 44^{\prime} \mathrm{E}\right)$. Traps were located at three elevations in the mountainous terrain: three plots at 25-91 m.a.s.1. in the floodplain forests, two plots in the beech forest, and grass meadow at 530 and 676 m.a.s.l. and five meadow plots at 1018-2260 m.a.s.l. in high mountains. In total, 369 specimens of $C$. exaratus we measured.

\subsection{Morphometric analysis}

Since the patterns of sexualdimorphism (SD) for different characters in individualsof the same species can vary [1], six morphometric characters of ground beetleswere taken in our analysis. Morphometric measurementswere carried out under an MBS-9 binocularmicroscope at a magnification of $1 \times 8$. After determiningthe sex of each beetle, six-dimensional features were assessed using an eyepiece micrometer: thelength of the elytra - the distance along the seam fromthe middle of the edge to the apex, elytra width thedistance between shoulder angles of the left and right elytra,pronotum length - midline distance from base toapex, pronotum width - base width, head length - distancefrom neck to upper lip, and the distance between eyes. In $C$. exaratus the measuring was done using "Manual Carabid morphometric measurement for the method by Sukhodolskaya" [22].Initial code of the 
latter is available under the free - permissive license MIT.

\subsection{Statistical processing}

The calculations we performed in the environment of the statistical system $\mathrm{R}$ in the smatr package [23]. To assess the effect of elevation on the size of the ground beetlesa linear model was used, in which a different intercepts were used for each sex, and the significance of the difference in slope for different sexes was estimated. To assess the significance, the Student's tstatistic was used. Thus, we estimate the difference in the effect of elevation between the sexes against the background of natural size variability. The calculations were carried out for each trait separately

\section{Results and Discussion}

In C. odoratus factor "Sex" affected elytra length and the head width, factor "Elevation" affected elytra and head parameters and pronotum length and in no case, we found $\mathrm{Sex} *$ Elevation interaction. All regression slopes showed trait values decline (except pronotum width) as illustrated in Fig 1.

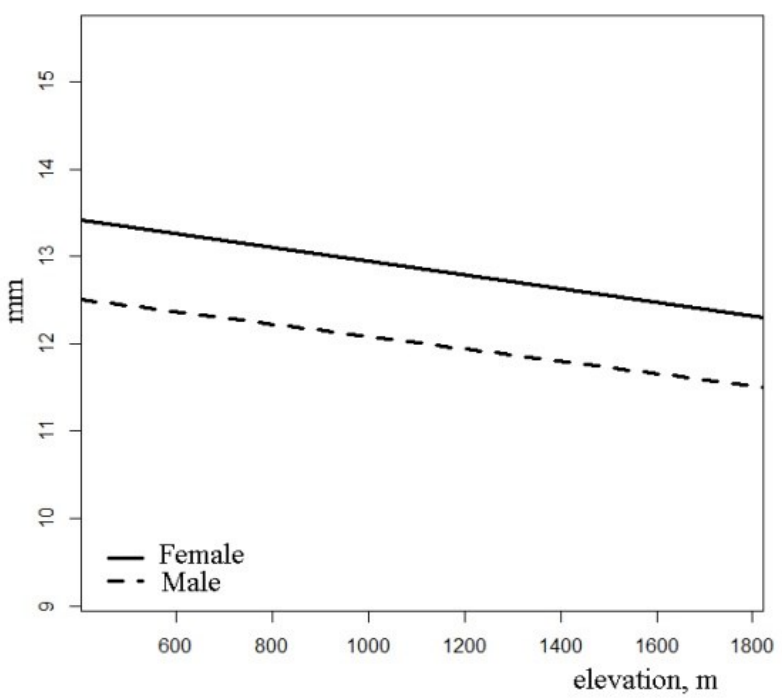

Fig. 1. Dependence of $C$. odoratus elytra length on elevation. Results of regression analysis. Regression slopes are similar in both sexes (p-value $=0.574)$

In Pt. montanus factor "Sex" affected elytra length, pronotum, and head parameters, factor "Elevation" affected elytra parameters and head length but not pronotum parameters and we found the only one case of those factors interaction in relation to the elytra width (Fig. 2). In that case, females' traits increased in altitude gradient, but males ones decreased. Other traits varied in both sexes similarly and in pronotum variation regression slopes practically overlapped.

In C. exaratus factor "Sex" affected only elytra parameters, factor "Elevation" - only head width and we found their interaction in relation to elytra, pronotum, and head width. In that, species regression slopes in females and males differed significantly: in females they went up but in males- went down (Fig. 3). Thus only in 4 traits out of 18 analyzed the steepness on traits variation in altitude gradient was sex-biased.

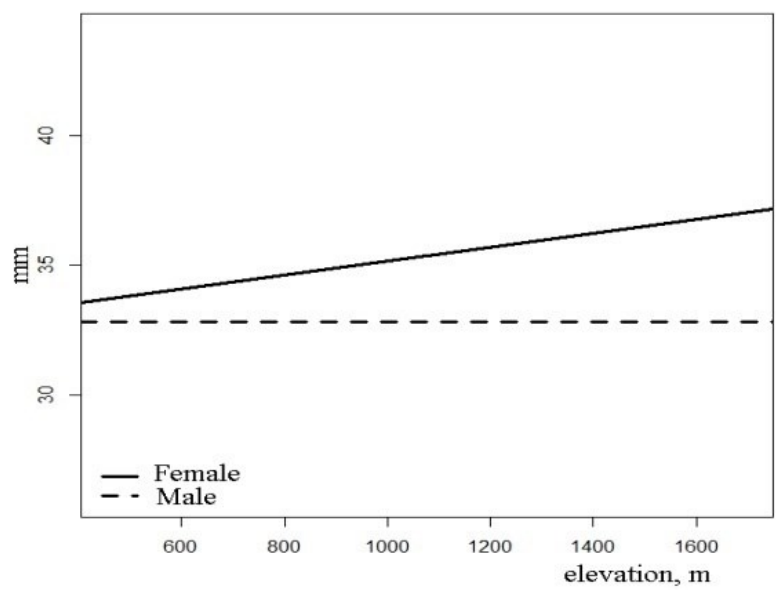

Fig. 2. Dependence of $P$. montanus elytra width on elevation. Results of regression analysis. Regression slopes are similar in both sexes ( $p$-value $=0.000)$

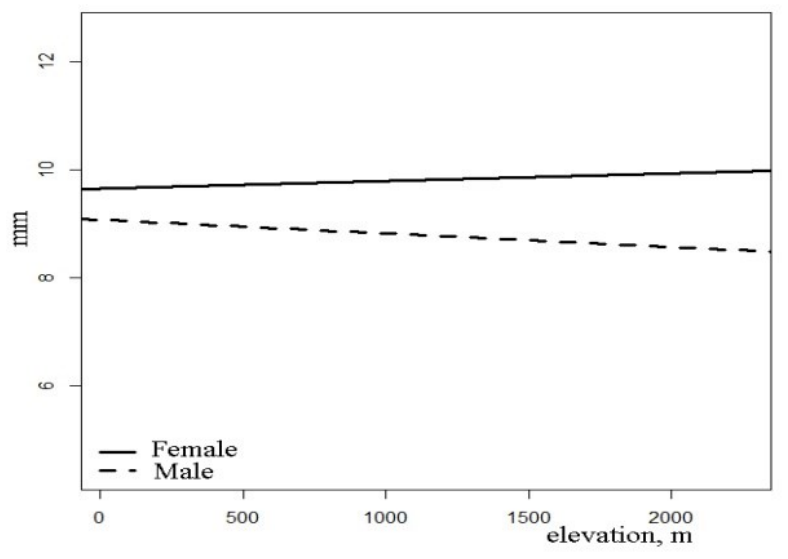

Fig. 3. Dependence of C. exaratus elytra width on elevation. Results of regression analysis. Regression slopes are similar in both sexes ( $\mathrm{p}$-value $=0.026$ )

Sexual dimorphism is ubiquitous in nature but its evolution is puzzling given that the mostly shared genome constrains independent evolution in the sexes. Sex differences should result from asymmetries between the sexes in selection or genetic variation but studies investigating both simultaneously are lacking. Here, we combined the field investigations with morphometric analysis in laboratory and subsequent modeling of results. The main advantage of our work was the fact that we sampled and measured beetles using the single methods and the sample size was large. Almost in all cases studied the traits varies similarly (regardless of region and species studied) in males and females, demonstrating that at each elevation we found unique population with its own mechanism of regulation. Nevertheless, regression slopes position indicated SSD presence in all species and at all 
elevations. It is noteworthy that SSD values coincided with populations density values. We calculated mean value of population density at each elevation during the period 1988-2020. In C. odoratus (except the coast, where the sample size was small) the lowest density was at middle mountains and the highest - at high mountains populations. And SSD variation curve in this species (when we averaged SSD values by all 6 traits) showed the same trend (Fig. 4, 5).

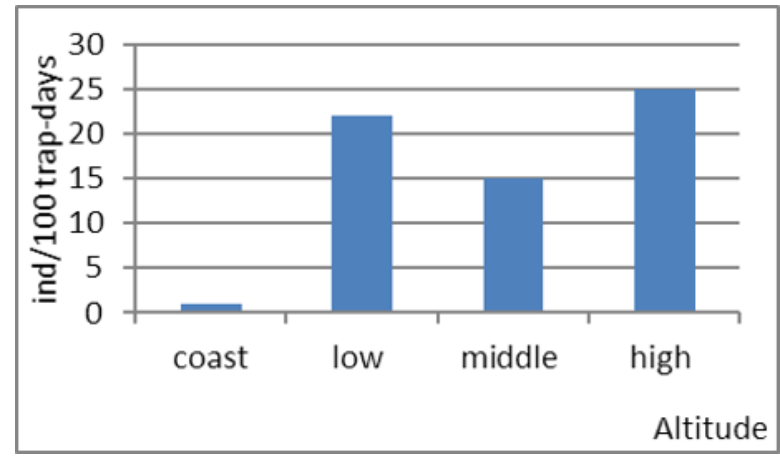

Fig.4. Density in C. odoratus populations

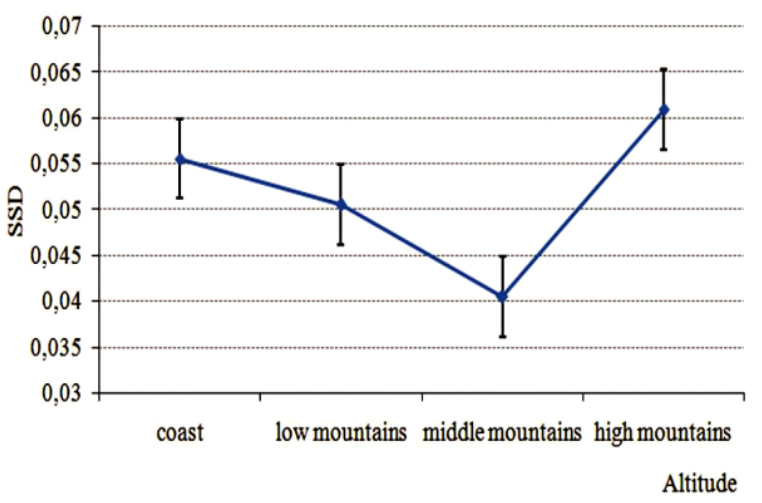

Fig.5. Averaged (for six dimensional characteristics) values of SD for C. odoratus

The same phenomena was observed in P. montanus. The highest averaged value in density in 1988-2020 was at low mountains. And exactly there we observed the highest values of SSD (Fig. 6, 7).

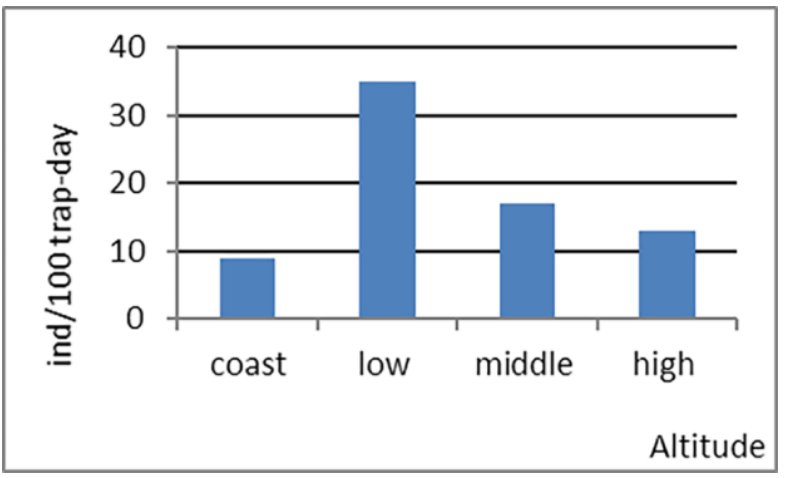

Fig. 6. Density in P. montanus populations

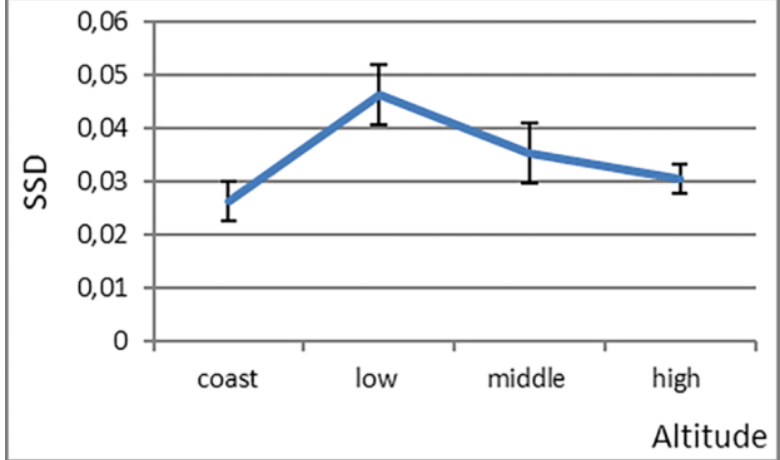

Fig.7. Averaged (for six dimensional characteristics) values of SD for P. montanus

While we can only speculate on possible mechanisms of such relationships. The most possible is the following. At high density resources are less available, so these conditions should be treated as unfavorable. Some authors think that in adverse environment SSD will increase [24].

The relationship between SSD and population number as well as the asymmetries between the sexes in selection or genetic variation should be the aims of further investigations.

Funding: This research was funded by the framework of the state assignment of the IEEB SB RAS, project 0271-2021-0001.

\section{References}

1. R.A. Sukhodolskaya, A.A. Saveliev, T.R. Muhammetnabiev, Res. J. Pharm., Biol. Chem. Sci. 7, 1992-2201 (2016)

2. R.A. Sukhodolskaya, A.A. Saveliev, A. Periodicum Biologorum, 118, 273-278 (2016)

3. R.A. Sukhodolskaya, T.L. Ananina, Asian Journal of Biology 2(2), 1-9 (2017)

4. R.A. Sukhodolskaya, A.A. Saveliev, Zoological Systematics 42(1), 71-89 (2017)

5. R.A. Sukhodolskaya, T.A. Avtaeva, V.V. Brigadirenko, A.L. Antsiferov, S.A. Kushalieva, Advances in Engineering Research 177, 10-15 (2018)

6. T.R. Mukhametnabiev, R.A. Sukhodolskaya, I.G. Vorobyova, A.L. Antsiferov, N.L. Ukhova, Russian Journal of Applied Ecology 1, 3-12 (2020)

7. N.I. Eremeeva, R.A. Sukhodolskaya, N.L. Ukhova, A.A. Saveliev GSCBPS 15, 104-111 (2021)

8. R.A. Sukhodolskaya, A.A. Saveliev, T.A. Gordienko, D.N. Vavilov, Sexual size dimorphism in Ground Beetles and its modeling in latitude gradient. GSCBPS 3(1), 11-18 (2018)

9. R.A. Sukhodolskaya, T.A. Avtaeva, A.A. Saveliev, D.N. Vavilov, Baltic J. Coleopterol., 19(1), 89100(2019)

10. R.A. Sukhodolskaya, T.L. Ananina, A.A. Saveliev Contemporary Problems of Ecology, 14, 62-70 (2021) 
11. T.L. Ananina, R.A. Sukhodolskaya, A.A. Saveliev, T.A. USJAS, 2020 4, 1-13 (2020)

12. R.A. Sukhodolskaya, T.A. Avtaeva, T.A. Gordienko, N.R. Vodunon, S.A. Kushalieva, Biodiversity in Caucasus and Southern Russia: levels, approaches, the state ofknowledge. (Makhachkala: ALEF, 2020)

13. W.U. Blanckenhorn, R.C. Stillwell, K.A. Young, C.W. Fox, K.G. Ashton, Evolution 60, 20042011(2006)

14. R.A. Sukhodolskaya, A.A. Saveliev, N.L. Ukhova, I.G. Vorobyova, I.A. Solodovnikov, A.L. Anciferov, T.A. Gordienko, R.R. Shagidullin, D.N. Vavilov, GSCBPS 13 (03), 149-161. (2020)

15. V.G. Shilenkov, S.M. Loshchev, Baikal. Zool. Zh. 2 (17), 22-38 (2015)

16. T.L. Ananina, Population Dynamics of Ground Beetles in Mountain Conditions of Northern CisBaikal Region (Ulan-Ude: Buryat. Gos. Univ., 2010)
17. D. Obydov, D. Mun, Entom. Zoology 1(1), 149 (2006)

18. V.G. Shilenkov, Ground Beetles of Carabus L. genus of Southern Siberia (Irkutsk University Publishing, Irkutsk, 1996).

19. T.A. Aydamirova, Bulletin of Moscow Society of Nature Researchers 116, 20-30 (2011)

20. E.E. Bokhovko, Life-cycles of ground beetles (Coleoptera, Carabidae) in the agrolandscape of Kubansk-Nearazov lowland south (Thesis Moscow, 2005)

21. L.N. Tyulina, Geobotanical Studies in the Baikal Reigon (Moscow, 1967)

22. T. R. Mukhametnabiev, Manual URL:https://github.com/CRTmatrix/-Manual

23. D.I. Warton, R.A. Duursma, D.S. Falster, S. Taskinen, Methods Ecol. Evol. 3, 257-259 (2012)

24. V.A. Geodakyan Two Sexes. Why? The Evolutionary Theory of Sex (Wilmington 2012) 